\title{
Growth-related changes in salt gland mass in gentoo and chinstrap penguin chicks
}

\author{
Youmin Kim, ${ }^{1}$ Min-Su Jeong, ${ }^{1}$ Hae-Min Seo, ${ }^{1}$ Hankyu Kim, ${ }^{1,2}$ Woo-Shin Lee ${ }^{1,3}$ \& Chang-Yong Choi ${ }^{1,3}$ \\ 'Department of Forest Sciences, Seoul National University, Seoul, Republic of Korea \\ 2Department of Forest Ecosystems and Society, Oregon State University, Corvallis, OR, USA \\ ${ }^{3}$ Research Institute of Agriculture and Life Sciences, Seoul National University, Seoul, Republic of Korea
}

\begin{abstract}
The salt gland is a well-developed osmoregulation organ in marine birds, and its relative size often reflects an individual's feeding environment and osmoregulation capability. The development and functions of salt glands have been described for the Adélie penguin (Pygoscelis adeliae), but this information has been poorly documented in the other two pygoscelid species: gentoo (P. papua) and chinstrap penguins ( $P$. antarcticus). To describe the growth-related changes in salt gland masses in relation to chick growth, we measured the wet mass of the salt glands collected from dead gentoo and chinstrap chicks during the early breeding period. The mass of the salt glands was linearly proportional to their body measurements, especially to body mass, in both species, and no significant difference was detected between the two species. Penguins are obligate marine dwellers throughout their life cycle, and the development of the salt gland in penguin chicks suggests that their ability to regulate dietary osmotic stress begins at an early stage of development after hatching. Furthermore, the linear relationship between the gland mass and body mass also suggests that the osmoregulation capability may continue to develop as penguin chicks grow. This descriptive note provides novel and quantitative information on the early developmental pattern of salt glands in gentoo and chinstrap penguins.
\end{abstract}

\author{
Keywords \\ Pygoscelis; salt gland; osmoregulation; \\ osmotic stress \\ Correspondence \\ Chang-Yong Choi, Research Institute of \\ E-mail: subbuteo@hanmail.net

Abbreviations
AIC: Akaike information criterion
BL: bill length
BM: body mass
df: degree of freedom
FL: flipper length
HL: head length
SP: species \\ Abbreviations \\ BL: bill length \\ BM: body mass \\ FL: flipper length \\ $\mathrm{HL}$ : head length
} Agriculture and Life Sciences, Seoul National University, Seoul 08826, Republic of Korea.

\section{Introduction}

Osmoregulation is essential for maintaining osmotic homeostasis in living organisms. Most vertebrates control the concentration of minerals in their body by filtering wastes from the kidneys and removing excess minerals via the excretory system (Schmidt-Nielsen 1960). Because birds have less developed kidneys than mammals, some groups of birds have salt glands to support osmoregulatory function (Schmidt-Nielsen 1960; Simon 1982). The salt gland can be observed above the eyes of many avian species (Marples 1932). To regulate osmotic pressure in the body, the gland excretes a highly concentrated salt solution that flows out through the nostrils (Schmidt-Nielsen 1960). The glands are especially well-developed in seabirds, consistent with the consumption of high-salt diets in marine environments (Schmidt-Nielsen 1960).

Salt gland development differs by species, and the size of the salt glands varies by sex, age and the saline level of their foraging habitats even in the same species (Ensor \& Phillips 1972; Siegel-Causey 1990; Woodin et al. 2008;
Gutiérrez et al. 2012). In some waterbirds, such as several Larus and Leucophaeus gull species (Ensor \& Phillips 1972; Dosch 1997), the common eider (Somateria mollissima; DeVink et al. 2005) and the white ibis (Eudocimus albus; Johnston \& Bildstein 1990), the chicks do not have completely developed salt glands when hatched, so the chicks may suffer from osmotic stress when they are fed high-saline diets. In such cases, their parents often selectively feed the chicks freshwater prey (Ensor \& Phillips 1972; Johnston \& Bildstein 1990; Dosch 1997; DeVink et al. 2005). Ducklings that were fed a high-salt content diet developed relatively larger salt glands during their growth (Ellis et al. 1963; Schmidt-Nielsen \& Kim 1964), and migratory redheads (Aythya americana) had heavier salt glands when they were exposed to higher osmotic loading (Woodin et al. 2008). Therefore, the developing salt gland, measured by its mass, could be a simple proxy of osmotic loading and osmoregulatory costs for birds experiencing changes in body conditions and environments.

The three Pygoscelis penguins-Adélie (Pygoscelis adeliae), gentoo (P. papua) and chinstrap penguins 
(P. antarcticus) - are obligate marine foragers, and a large proportion of prey delivered to chicks, chiefly crustaceans like krill (Volkman et al. 1980), contains a high level of salt concentration. Adélie penguin chicks have functionally complete salt glands immediately after hatching (Janes 1997), and the mass of the glands increases linearly with body mass (Douglas 1968). While Adélie penguins in the Ross Sea feed their chicks a relatively greater proportion of osmoneutral food (fish) (Ainley et al. 1998), chinstrap and gentoo penguins on King George Island in the South Shetland Islands rely almost entirely on Antarctic krill (Euphausia spp.), especially for chick-rearing (Lishman 1985; Trivelpiece et al. 1987; Kokubun et al. 2015). Such a difference in local food availability and the species-specific physiological differences might manifest in different salt gland development patterns in the pygoscelid chicks. Nevertheless, unlike in Adélie penguins, the growth of salt glands has been poorly documented in chinstrap and gentoo penguins.

The aim of this study was to describe the change in salt gland masses in relation to the early growth of gentoo and chinstrap penguin chicks at Narębski Point on King George Island, South Shetland Islands, maritime Antarctica. In particular, we tested whether salt glands developed linearly with chick growth, as previously shown in Adélie penguins, and we compared possible differences in salt gland development in the two pygoscelid species.

\section{Methods}

Narębski Point $\left(62^{\circ} 14^{\prime} 14.3^{\prime \prime}\right.$ S, 58 $\left.46^{\prime} 27.1^{\prime \prime} \mathrm{W}\right)$ is an Antarctic Specially Protected Area located on the south-east coast of Barton Peninsula on King George Island, in the Southern Shetland Islands, Antarctica. There are approximately 3000 pairs of chinstrap penguins and 2000 pairs of gentoo penguins every breeding season at Narębski Point (ATCM 2019). Those penguins breeding at Narębski Point rely on krill as the main food resource (Volkman et al. 1980), and krill have been found to constitute $80 \%$ of the prey of Pygoscelis penguin chicks at other breeding sites on King George Island (Trivelpiece et al. 1987).

A total of 72 carcasses of gentoo $(n=51)$ and chinstrap penguin $(n=21)$ chicks were collected during two breeding seasons from December 2017 to January 2018 and from December 2018 to February 2019. In the first season, 19 carcasses (12 gentoo and 7 chinstrap penguin chicks) were collected, and 53 carcasses (39 gentoo and 14 chinstrap penguin chicks) were collected in the second season. The dead chicks were 1-26 days old, based on our field observations and their body sizes, and they probably died of natural causes such as bad weather conditions. No sign of malnutrition was observed in general; 37 of
55 examined carcasses $(67 \%)$ held krill in their guts, and 45 of them $(82 \%)$ were in average or good condition in terms of body mass.

The carcasses of the chicks were stored in a freezer $\left(-70{ }^{\circ} \mathrm{C}\right)$ at the King Sejong Station until measured and processed. The flipper length ( $\mathrm{mm}$, from shoulder to tip) was measured with a ruler, bill and head lengths (mm) with callipers and body mass (g) with a Pesola spring scale. Two salt glands were carefully extracted from each bird with scalpels and forceps, and the wet mass of the more intact gland of the two extracted ones was measured to a precision of $0.00001 \mathrm{~g}$ with a Mettler Toledo digital scale (model AE 240-S).

We compared eight linear mixed models to select the best predictor out of four measured body sizes that represent the size of the salt glands by species. Therefore, the fixed-effect parameters for the models were four body measurements (body mass, flipper length, bill length and head length) and species, while the year was used as a random effect parameter. The models that best described the variability in salt gland mass were selected using the AIC, and we determined the influence of the fixed effects to the wet mass of the gland with the full averaged model when more than two candidate models showing $\triangle \mathrm{AIC}<2$ were identified (Burnham \& Anderson 2004). The coefficient and linear regression equation between the wet mass of the gland and the body measurements from the averaged model were shown on each species, and the combined values of both species were shown if the species did not significantly affect the gland mass. We used the nlme (Pinheiro et al. 2015) and MuMIn packages (Barton 2018) in R 3.4.3 (R Core Team 2014) for all statistical analyses.

\section{Results}

The body mass of all the collected carcasses ranged from $45 \mathrm{~g}$ to $2415 \mathrm{~g}$, and the individual mass of their salt glands ranged from $0.00996 \mathrm{~g}$ to $0.94493 \mathrm{~g}$ (Fig. 1). Two models with body mass and species parameters were the best candidate models showing the lowest AIC values ( $\triangle \mathrm{AIC}$ $<2$; Table 1), but the effect of species on the wet mass of the salt glands was not significant in the averaged model (Table 2). Therefore, though the wet mass of the salt glands increased proportionally to all body measurements of the penguin chicks, the body mass was selected as the best criterion for salt gland growth. The body mass and the salt gland mass were highly correlated (gentoo: $r^{2}=0.92, p<0.001$; chinstrap: $r^{2}=0.91, p<0.001$; combined: $r^{2}=0.92, p<0.001$; Fig. 1). The salt gland size relative to body size was $0.34 \mathrm{mg} / \mathrm{g}$ and $0.36 \mathrm{mg} / \mathrm{g}$ in gentoo and chinstrap chicks, respectively, while it was $0.26 \mathrm{mg} / \mathrm{g}$ in Adélie penguin chicks (Table 3). 

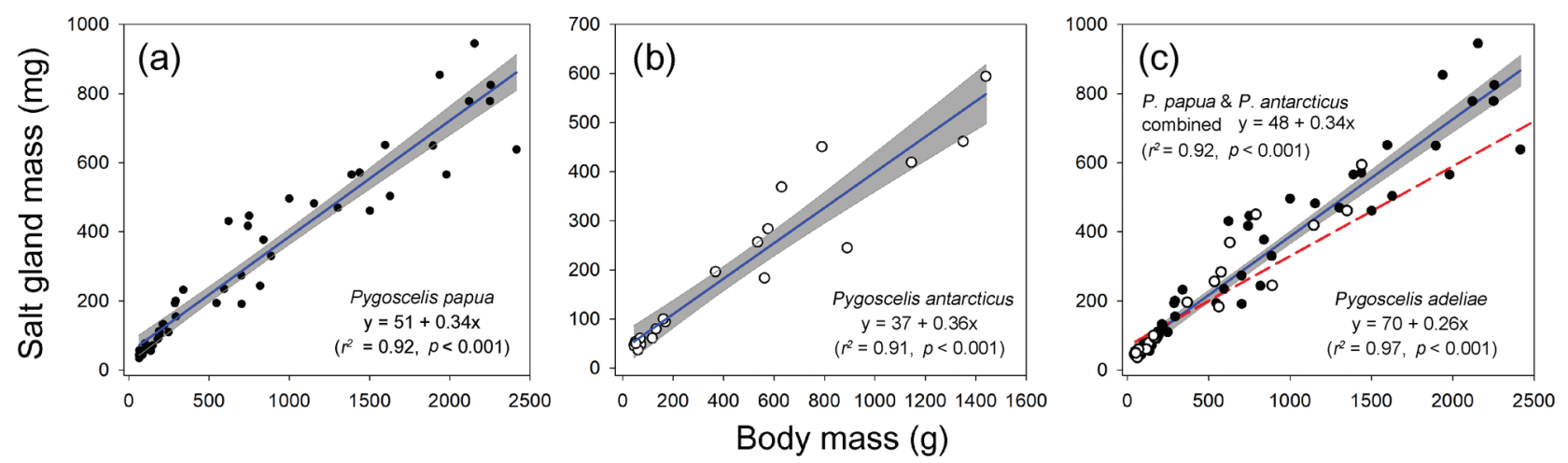

Fig. 1 Relationship of the salt gland mass (mg) to body mass (g) in (a) gentoo penguins (Pygoscelis papua; filled circles), (b) chinstrap penguins (P. antarcticus; open circles) and (c) the two combined species. A linear regression line (solid blue line) and its $95 \%$ confidence band (grey shading) for the estimate of the regression were marked. The red dashed line (c) indicates the linear regression in the Adélie penguin (P. adeliae; data from Douglas [1968]).

Table 1 Summary of the candidate models that predicted the salt gland mass of the chicks of the chinstrap and gentoo penguins.

\begin{tabular}{|c|c|c|c|c|c|}
\hline Rank & Model $^{a}$ & df & AIC score & $\triangle \mathrm{AIC}$ & $\mathrm{AlC}_{\mathrm{w}}{ }^{\mathrm{b}}$ \\
\hline 1 & $\mathrm{BM}, \mathrm{SP}$ & 5 & 822.1 & 0.00 & 0.67 \\
\hline 2 & $B M, S P, B M * S P$ & 6 & 823.9 & 1.86 & 0.27 \\
\hline 3 & $\mathrm{HL}, \mathrm{SP}, \mathrm{HL} \star \mathrm{SP}$ & 6 & 827.8 & 5.78 & 0.04 \\
\hline 4 & $\mathrm{FL}, \mathrm{SP}, \mathrm{FL} \star \mathrm{SP}$ & 6 & 828.9 & 6.88 & 0.02 \\
\hline 5 & $\mathrm{FL}, \mathrm{SP}$ & 5 & 834.6 & 12.57 & 0.00 \\
\hline 6 & $\mathrm{HL}, \mathrm{SP}$ & 5 & 835.6 & 13.54 & 0.00 \\
\hline 7 & $\mathrm{BL}, \mathrm{SP}, \mathrm{BL} * \mathrm{SP}$ & 6 & 836.8 & 14.75 & 0.00 \\
\hline 8 & $\mathrm{BL}, \mathrm{SP}$ & 5 & 854.5 & 32.41 & 0.00 \\
\hline
\end{tabular}

${ }^{a}$ Asterisks between parameters represent interactions between them. ${ }^{\mathrm{b}} \mathrm{A}$ relative likelihood of the model based on the AIC score.

Table 2 Model averaged parameter estimates, standard errors and $p$ values from the best linear models explaining the mass of the salt glands in the chinstrap and gentoo penguin chicks.

\begin{tabular}{lcrc}
\hline Variables $^{\text {a }}$ & Estimates & \multicolumn{1}{c}{ SE } & $p$ value \\
\hline Intercept & 44.60 & 17.83 & 0.014 \\
Body mass & 0.35 & 0.02 & $<0.001$ \\
Species & 4.11 & 20.93 & 0.847 \\
Body mass * Species & -0.01 & 0.02 & 0.745 \\
\hline
\end{tabular}

${ }^{a}$ Asterisks between parameters represent interactions between them.

\section{Discussion}

Douglas (1968) suggested that the osmoregulation capability of the salt gland per unit mass was unchanged in Adélie penguin chicks because their salt gland mass was linearly proportional to their body mass. Similarly, the salt gland mass showed a linear relationship with the body mass in the gentoo and chinstrap penguin chicks in this study, suggesting that their chicks already have a
Table 3 The linear regression between the salt gland mass (mg) and the body mass (g) in Pygoscelis penguin chicks.

\begin{tabular}{lccl} 
Species & Slope & Intercept & Source \\
\hline Adélie penguin (P. adeliae) & 0.26 & 70.00 & Douglas 1968 \\
Gentoo penguin (P. papua) & 0.34 & 50.55 & This study \\
Chinstrap penguin (P. antarcticus) & 0.36 & 37.48 & This study \\
\hline
\end{tabular}

functioning salt gland that can control the osmotic pressures in the body immediately after hatching.

There was no difference between the chicks of the two penguin species in the salt gland growth, likely because both species feed mainly on krill in the same foraging environment in maritime Antarctica (Volkman et al. 1980; Trivelpiece et al. 1987). The salt gland mass of the two species was linearly proportional to the body mass; the relative salt gland masses of the chicks were indistinguishable from that of Adélie chicks, especially in the early stage of growth, but slightly heavier in the later stages probably due to their larger body sizes (see Table 3, Fig. 1). Although gentoo and chinstrap penguins may use more high-saline diets (Trivelpiece et al. 1987), this finding suggests that all the young chicks of the three pygoscelid penguins generally adapted to a similar saline level. However, these interspecific differences, measured in different sites, years, and sample sizes, can be further examined by comparing the specific development patterns of the salt glands with more samples collected at the same sites and seasons.

The relative size of the salt glands of all three pygoscelid penguins $(0.26-0.36 \mathrm{mg} / \mathrm{g})$ may be relatively smaller than those of fish-eating pelagic cormorants $(2-3 \mathrm{mg} / \mathrm{g}$ [Thomson \& Morley 1966]) or shorebirds (0.4-0.8 mg/g in marine fish eaters and $0.5-1.2 \mathrm{mg} / \mathrm{g}$ in oceanic invertebrate eaters [Staaland 1967]). The excretory osmotic pressure of the Adélie penguin is known to be higher 
than that of other seabirds and that the excreted solution of its chicks has an especially high chloride ion concentration (Janes 1997). Therefore, the pygoscelid chicks seem to have a more efficient salt gland for osmoregulation compared to other species, enabling them to adapt to a high-salt environment with a relatively small salt gland.

This descriptive note provides novel and quantitative information on the developmental pattern of salt glands in gentoo and chinstrap penguin chicks early in their growth. Our data suggest that these two penguins may minimize saline stress by having a small but functional salt gland even at a very early stage in life, similar to Adélie penguins. Furthermore, the linear relationship between the salt gland mass and body mass also suggests that their osmoregulation capability develops as the chicks grow. However, the salt gland mass itself may not fully and directly represent the true osmoregulation capability. Because detailed information on the physiological functions of salt glands is still lacking for these two species, more experimental, anatomical and physiological studies will help bridge the current knowledge gap in osmoregulation in the pygoscelid penguins.

\section{Acknowledgements}

The authors thank the Korea Polar Research Institute and King Sejong Station for their support to our field studies in Antarctica. This study was performed with permission from the Korean Ministry of Foreign Affairs in accordance with the Act on Antarctic Activities and Protection of Antarctic Environment.

\section{Funding}

The Korean Ministry of Environment funded this study, as part of a long-term ecosystem monitoring in the Antarctic Specially Protected Area no. 171 on King George Island.

\section{Disclosure statement}

The authors report no conflict of interest.

\section{References}

Ainley D.G., Wilson P.R., Barton K.J., Ballard G., Nur N. \& Karl B. 1998. Diet and foraging effort of Adélie penguins in relation to pack-ice conditions in the southern Ross Sea. Polar Biology 20, 311-319, doi: 10.1007/s003000050308.

ATCM (Antarctic Treaty Consultative Meeting) 2019. Revised Management Plan for Antarctic Specially Protected Area no. 171,
Narębski Point, Barton Peninsula, King George Island. Working Paper 16. Antarctic Treaty Consultative Meeting XLII and Committee for Environmental Protection Meeting XXII, 1-11 Jul 2019. Prague.

Barton K. 2018. MuMIn: multi-model inference. R package version 1.40.4. Accessed on the internet at https:// CRAN.R-proje ct.org/package=MuMIn on 1 July 2019.

Burnham K.P. \& Anderson D.R. 2004. Multimodel inference: understanding AIC and BIC in model selection. Sociological Methods e Research 33, 261-304, doi: 10.1177/0049124104268644.

DeVink J.-M.A., Gilchrist H.G. \& Diamond A.W. 2005. Effects of water salinity on growth and survival of common eider (Somateria mollissima) ducklings. Auk 122, 523-529, doi: 10.1093/auk/122.2.523.

Dosch J.J. 1997. Salt tolerance of nestling laughing gulls: an experimental field investigation. Colonial Waterbirds 20, 449-457, doi: 10.2307/1521595.

Douglas D.S. 1968. Salt and water metabolism of the Adélie penguin. Antarctic Bird Studies 12, 167-190.

Ellis R.A., Goertemiller C.C. Jr., DeLellis R.A. \& Kablotsky Y.H. 1963. The effect of a salt water regimen on the development of the salt glands of domestic ducklings. Developmental Biology 8, 286-308, doi: 10.1016/0012-1606(63)90031-9.

Ensor D. \& Phillips J. 1972. The effect of age and environment on extrarenal salt excretion in juvenile gulls (Larus argentatus and L. fuscus). Journal of Zoology 168, 119-126, doi: $10.1111 / \mathrm{j} .1469-7998.1972 . t b 01342 . x$.

Gutiérrez J.S., Dietz M.W., Masero J.A., Gill Jr R.E., Dekinga A., Battley P.F., Sánchez-Guzmán J.M. \& Piersma T. 2012. Functional ecology of saltglands in shorebirds: flexible responses to variable environmental conditions. Functional Ecology 26, 236-244, doi: 10.1111/j.1365-2435.2011.01929.x.

Janes D.N. 1997. Osmoregulation by Adélie penguin chicks on the Antarctic peninsula. Auk 114, 488-495, doi: $10.2307 / 4089249$.

Johnston J.W. \& Bildstein K.L. 1990. Dietary salt as a physiological constraint in white ibis breeding in an estuary. Physiological Zoology 63, 190-207, doi: 10.1086/ physzool.63.1.30158161.

Kokubun N., Lee W.Y., Kim J.H. \& Takahashi A. 2015. Chinstrap penguin foraging area associated with a seamount in Bransfield Strait, Antarctica. Polar Science 9, 393-400, doi: 10.1016/j.polar.2015.10.001.

Lishman G.S. 1985. The food and feeding ecology of Adélie penguins (Pygoscelis adeliae) and chinstrap penguins ( $P$. antarctica) at Signy Island, South Orkney Islands. Journal of Zoology 205, 245-263, doi: 10.1111/j.1469-7998.1985. tb03532.x.

Marples B. 1932. The structure and development of the nasal glands of birds. Journal of Zoology 102, 829-844, doi: $10.1111 / \mathrm{j} .1096-3642.1932 . t b 01565 . x$.

Pinheiro J., Bates D., DebRoy S., Sarkar D. \& R Core Team 2015. nlme: linear and nonlinear mixed effects models. $\mathrm{R}$ package version 3.1. Accessed on the internet at http:// CRAN.R-project.org/package=nlme on 1 July 2019. 
R Core Team 2014. R: a language and environment for statistical computing. Vienna: R Foundation for Statistical Computing.

Schmidt-Nielsen K. 1960. The salt-secreting gland of marine birds. Circulation 21, 955-967, doi: 10.1161/01. CIR.21.5.955.

Schmidt-Nielsen K. \& Kim Y.T. 1964. The effect of salt intake on the size and function of the salt gland of ducks. Auk 81 , 160-172, doi: 10.2307/4082766.

Siegel-Causey D. 1990. Phylogenetic patterns of size and shape of the nasal gland depression in Phalacrocoracidae. Auk 107, 110-118, doi: 10.1093/auk/107.1.110.

Simon E. 1982. The osmoregulatory system of birds with salt glands. Comparative Biochemistry and Physiology 71, 547-556, doi: 10.1016/0300-9629(82)90203-1.

Staaland H. 1967. Anatomical and physiological adaptations of the nasal glands in Charadriiformes birds.
Comparative Biochemistry and Physiology 23, 933-944, doi: 10.1016/0010-406X(67)90354-4.

Thomson J. \& Morley N. 1966. Physiological correlates of habitat selection in Australian cormorants. Emu 66, 17-26, doi: 10.1071/MU966017.

Trivelpiece W.Z., Trivelpiece S.G. \& Volkman N.J. 1987. Ecological segregation of Adélie, gentoo, and chinstrap penguins at King George Island, Antarctica. Ecology 68, 351-361, doi: 10.2307/1939266.

Volkman N.J., Presler P. \& Trivelpiece W. 1980. Diets of pygoscelid penguins at King George Island, Antarctica. Condor 82, 373-378, doi: 10.2307/1367558.

Woodin M., Michot T. \& Lee M. 2008. Salt gland development in migratory redheads (Aythya americana) in saline environments on the winter range, Gulf of Mexico, USA. Acta Zoologica Academiae Scientiarum Hungaricae 54, 251-264. 